(c) 2020, The Authors. Published by FASS Inc. and Elsevier Inc. on behalf of the American Dairy Science Association ${ }^{\circledR}$. This is an open access article under the CC BY-NC-ND license (http://creativecommons.org/licenses/by-nc-nd/4.0/).

\title{
Associations of reproductive indices with fertility outcomes, milk yield, and survival in Holstein cows
}

\author{
P. Pinedo, ${ }^{1 *}$ J. E. P. Santos, ${ }^{2}$ R. C. Chebel, ${ }^{3}$ K. N. Galvão, ${ }^{3}$ G. M. Schuenemann, ${ }^{4}$ R. C. Bicalho, ${ }^{5}$ R. O. Gilbert, ${ }^{6}$ \\ S. L. Rodriguez-Zas, ${ }^{7}$ C. M. Seabury ${ }^{8}$ G. Rosa, ${ }^{9}$ and W. Thatcher ${ }^{2}$ \\ ${ }^{1}$ Department of Animal Sciences, Colorado State University, Fort Collins 80521 \\ ${ }^{2}$ Department of Animal Sciences, University of Florida, Gainesville 32611 \\ ${ }^{3}$ College of Veterinary Medicine, University of Florida, Gainesville 32611 \\ ${ }^{4}$ College of Veterinary Medicine, The Ohio State University, Columbus 43210 \\ ${ }^{5}$ College of Veterinary Medicine, Cornell University, Ithaca, NY 14850 \\ ${ }^{6}$ School of Veterinary Medicine, Ross University, Basseterre, Saint Kitts and Nevis, West Indies \\ ${ }^{7}$ Department of Animal Sciences, University of Illinois, Urbana-Champaign 61801 \\ ${ }^{8}$ College of Veterinary Medicine, Texas A\&M University, College Station 77843 \\ ${ }^{9}$ Department of Animal Sciences, University of Wisconsin, Madison 53706
}

\section{ABSTRACT}

The study is part of a research effort investigating potential associations between genomic variation and fertility of Holstein cows. The objective was to compare the reproductive performance of Holstein cows in 3 categories of 2 reproductive indices (RI) that were developed for the allocation of cows in a ranking for potential fertility, based on the predicted probability of pregnancy. The associations between categories of the developed indices and multiple fertility variables in a large multistate population of Holstein cows were tested. In addition, we analyzed associations among the RI categories with milk yield and survival. Based on phenotypic information from individual cows, 2 reproductive indices (RI1 and RI2) were developed, representing a predicted probability that a cow will become pregnant at first artificial insemination postpartum, as a function of explanatory variables used in a logistic model. Data from a total of 11,733 cows calving in 16 farms located in 4 regions of the United States (Northeast, Midwest, Southeast, and Southwest) were available. Cows were enrolled at parturition and monitored weekly for reproductive events, health status, milk yield, and survival. To develop the indices, potential significant effects were initially tested by univariate analyses. Effects with $P \leq$ 0.05 were offered to the multivariate analysis, and the final models were determined through backward elimination, considering potentially significant interactions. The final model for RI1 included the random effect of farm and a complement of significant fixed effects as explanatory variables influencing a pregnancy outcome: (1) incidence of retained fetal membranes; (2) metritis;

Received November 7, 2019.

Accepted February 17, 2020.

*Corresponding author: pinedop@colostate.edu
(3) clinical endometritis; (4) lameness at 35 days in milk (DIM); (5) resumption of postpartum ovulation by 50 DIM; (6) season of calving; and (7) parity number. The model for RI2 included (1) parity number; (2) body condition score at 40 DIM; (3) incidence of retained fetal membranes; (4) metritis; (5) resumption of postpartum ovulation by 50 DIM; (6) region; (7) subclinical ketosis; (8) mastitis; (9) clinical endometritis; and (10) milk yield at the first milk test after calving; as well as the interaction effects of postpartum resumption of ovulation by 50 DIM $\times$ region; mastitis $\times$ region; and milk yield at the first milk test after calving $\times$ parity number. Multivariate logistic regression, ANOVA, and survival analysis were used to test the correspondence between the resulting RI and individual fertility, milk yield, and survival from the population. To facilitate the analyses, the resulting RI values were categorized as low for cows in the lowest quartile, medium for cows within the interquartile range, or high for cows in the top quartile. We found consistent agreement between categories of the predicted RI and the measures of fertility and survival collected from individual cows. We conclude that the proposed RI represent a viable approach to refine the allocation of cows into potential low- and high-fertility populations.

Key words: fertility, index, milk yield, survival

\section{INTRODUCTION}

Fertility is a critical component of efficient dairy production, and failures to attain and maintain a timely pregnancy are major reasons for production losses in dairy herds. Consequences of low fertility include a reduced percentage of cows at the early stages of lactation, increases in insemination costs, and delayed genetic progress (Santos et al., 2010). Moreover, impaired fertility leading to low milk production has been 
reported as one of the most frequent reasons for culling (Pinedo and de Vries, 2010).

Multiple variables have been identified as factors contributing to a persistent decline in fertility of dairy cows during recent decades (Lucy, 2001; Santos et al., 2004; Weigel, 2006; Norman et al., 2009). Failure to optimize reproductive control, inadequate nutritional management, and occurrence of diseases, combined with intense increases in genetic potential of milk yield, have contributed, at least in part, to the problem (Lucy, 2001; Royal et al., 2002). Particularly, early embryonic mortality in lactating dairy cows is substantial and likely one of the main causes of infertility (Santos et al., 2004; Diskin et al., 2006).

Metabolic and uterine diseases have important effects on reproductive efficiency in dairy herds because of their negative implications and their associations with other fertility stressors, such as anovulation and loss of body condition early in lactation (Santos et al., 2010; Ribeiro et al., 2016). The risk for poor health is higher during the transition period, as negative energy balance and immune suppression concur, making cows susceptible to infectious diseases and metabolic disorders (Bell et al., 1995; Esposito et al., 2014). However, the detrimental effects of disease conditions extend beyond this period, affecting subsequent biological processes such as conception and embryo survival (Ribeiro et al., 2016; Carvalho et al., 2019).

Historically, outcomes such as peak milk production or survival, specific biomarkers (nonesterified fatty acid and BHB serum concentrations), and herd removal rates by 60 DIM have been used to monitor transition success at the herd level (Pinedo et al., 2010; Roberts et al., 2012; Wisnieski et al., 2019). The use of health outcome records also has been proposed, with variable success due to inconsistencies in disease definitions, detection, and recording (Nordlund and Cook, 2004; Moyes et al., 2013; Lukas et al., 2015). However, the ability of a cow to cope with critical events during the transition period could provide an indicator of future success of reproductive and milk yield performance. One metric that has been proposed as a measure of early-lactation health and performance is the Transition Cow Index (Nordlund and Cook, 2004; Nordlund, 2006; Nordlund et al., 2011; Schultz et al., 2016), which considers the difference between actual and predicted milk production at the first DHI test, expressed on a 305-d basis. Interestingly, high values for this index were significantly correlated with other predictors that are characteristic of well-managed herds, such as milk production and udder health (Brotzman et al., 2015).

Methodologies refining the identification of cows with low and high potential for fertility would be valuable tools for research in multiple management areas.
The study reported here is part of a research effort investigating potential associations between genomic variation and fertility of Holstein cows. The proposed approach was to develop indices allowing for the allocation of cows in a ranking for potential fertility, based on the predicted probability of pregnancy. In this study, 2 reproductive indices ( $R \mathbf{R})$ predicting the individual probability of pregnancy at first AI were developed, based on data from a multistate population of Holstein cows. Information was prospectively collected from cows enrolled at calving and monitored on a weekly basis, using standardized disease definitions.

We hypothesized that individual values for the proposed RI would be associated with multiple reproductive variables measuring cow fertility. Therefore, the objective of this study was to compare the reproductive performance of Holstein cows in 3 categories of 2 RI. Toward that end, the associations between categories of the developed indices and multiple fertility variables in a large multistate population of Holstein cows were tested. In addition, the associations among the RI categories with milk yield and survival were analyzed.

\section{MATERIALS AND METHODS}

\section{Study Population and Monitoring Procedures}

This study included a total of 11,733 Holstein cows calving from November 2012 to October 2014 in 16 dairy herds located in 4 regions of the United States: the Northeast (2,635 cows in 4 herds), Midwest $(5,189$ cows in 6 herds), Southeast (1,183 cows in 1 herd), and Southwest (2,726 cows in 5 herds). Cows were enrolled at parturition and monitored weekly for reproductive events and health status.

Monitoring of disease was performed in weekly visits to the study farms. The following procedures were used. (1) Evaluation of vaginal discharge at $7 \pm 3$ DIM and $28 \pm 7$ DIM, using a 0 to 5 scoring system: $0=$ no mucus, $1=$ crystalline, $2=$ flecks of pus, $3=$ mucopurulent $<50 \%$ pus, $4=$ purulent $>50 \%$ pus, $5=$ watery reddish or brownish fetid discharge (McDougall et al., 2007). (2) Collection of blood samples at $7 \pm 3$ DIM for determination of serum BHB. (3) Lameness scoring at $35 \pm 3$ DIM using a 1 to 5 scoring system: $1=$ normal, $2=$ mildly lame (stands with flat back but arches when walks; gait slightly abnormal), $3=$ moderately lame (stands and walks with arched back), $4=$ lame (arched back standing and walking, one or more limbs favored), $5=$ severely lame (arched back, refuses to bear weight in one limb, great difficulty moving from lying position); modified from Bicalho et al. (2007).

Events of interest included calving-related events (dystocia, stillbirth, and twins, determined via farm 
records), retained fetal membranes (membranes not expelled after $24 \mathrm{~h}$ post-calving; Kelton et al., 1998), metritis $(7 \pm 3$ DIM, mucus score 5 ; McDougall et al., 2007), subclinical ketosis ( $7 \pm 3$ DIM, serum BHB $>1.0$ $\mathrm{mmol} / \mathrm{L}$; Overton et al., 2017), clinical endometritis (28 \pm 7 DIM, mucus score $>2$; McDougall et al., 2007), clinical mastitis (farm records, binary score of 0 or 1 ), left displaced abomasum (farm records, 0 or 1 ), pneumonia (farm records, 0 or 1 ), and lameness (35 \pm 3 DIM, score $>2$; Bicalho et al., 2007).

Reproductive outcomes included resumption of postpartum ovulation, which was assessed via transrectal ultrasonography or via determination of serum concentration of progesterone at $40 \pm 3$ and $54 \pm 3$ DIM. Anovulation was defined as lack of visible corpus luteum on both consecutive ultrasound scans or progesterone concentration $<1 \mathrm{ng} / \mathrm{mL}$ in both serum samples (Cerri et al., 2004; Bicalho et al., 2008). Pregnancy was diagnosed via ultrasonography on d $32 \pm 3$ after AI and reconfirmed at d $60 \pm 3$ of gestation. Pregnancy loss between d 32 and 60 was calculated from the proportion of cows diagnosed pregnant at $32 \pm 3$ but nonpregnant at $60 \pm 3 \mathrm{~d}$ after AI.

The indices were subsequently populated with the following data: (1) calving-related problems, (2) sex of calf, (3) metritis $(7 \pm 3 \mathrm{DIM})$ and endometritis (28 \pm 7 DIM), (4) resumption of postpartum ovulation, (5) detection of estrus after prostaglandin $\mathrm{F}_{2 \alpha}$ administered on $\mathrm{d} 54 \pm 3$ postpartum (estrus between $54 \pm 3$ and 61 \pm 3 postpartum), (6) pregnancy diagnosis for the first 2 AI (32 \pm 3 d after AI), (7) reconfirmation of pregnancy (d $60 \pm 3$ of gestation), (8) subclinical ketosis $(7 \pm 3$ DIM), and (9) BCS at calving and $40 \pm 3$ DIM (Ferguson et al., 1994). The following information was also included: (10) general and production cow data: parity number, milk yield [DHI test day milk (TDM) yield performed monthly and recorded until 305 DIM], milk composition, and season of calving; (11) breeding information: time to first AI and pregnancy, AI per pregnancy; (12) management-related data: breeding program, voluntary waiting period; (13) health-related events; and (14) live culling and death. A summary of the frequencies of health-related conditions, average BCS, average milk yield at 90 DIM, and reproductive and survival variables by geographic region are presented in Table 1.

\section{Reproductive Indices}

Based on phenotypic information from individual cows, 2 reproductive indices (RI1 and RI2) were developed, representing a predicted probability that a cow will become pregnant at first AI as a function of explanatory variables used in a logistic model. The rationale for developing and subsequently testing 2 indices was to emphasize reproductive events in RI1 and consider other health disorders, milk yield, the effect of geographic region (instead of herd), and interaction terms in RI2.

Data from 11,733 cows were initially considered. Univariate models for pregnancy outcome at first AI postpartum (AI1), based on the pregnancy diagnosis at $60 \mathrm{~d}$ after AI, were initially assessed and included the single fixed effect of a predictor and the random effect of herd. Cows leaving the herd (live culling or death) and cows that were determined as "do not breed" by farm management before an outcome for AI1 was established were excluded from the analyses. The single predictors in the analyses included season of calving (winter vs. summer), parity (primiparous vs. multiparous), BCS at calving and at 40 DIM, and BCS change from 0 to 40 DIM (categorized as lost, no change, or gained). Binary independent variables (i.e., predictors) examined in the series of univariable models included dystocia, twins, stillbirth, retained fetal membranes, subclinical ketosis (BHB $>1.0 \mathrm{mmol} / \mathrm{L}$ ), metritis, mastitis, displaced abomasum, lameness, respiratory disease, clinical endometritis, estrous cyclicity, and estrus before AI. In addition, method of AI (estrus vs. use of estrus synchronization protocol) and average daily milk yield in the first 90 DIM (M90; continuous) were also considered as predictors in the models.

Both RI were developed as a continuous variable, originating from the probability equation of the logistic regression model, ranging from 0 to 1 , and directly related to the probability of pregnancy: $\mathrm{P}$ (pregnancy $\mid \alpha, \beta$ ) $=\mathrm{e}^{\Sigma \beta i Z i+\mu \sigma} / 1+\mathrm{e}^{\Sigma \beta \mathrm{iZi}+\mu \sigma}$, where $\mathrm{e}$ is the base of natural logarithms, $\mathrm{P}$ (pregnancy $\mid \alpha, \beta$ ) is the predicted probability that a cow will be pregnant at AI1 (confirmed at the pregnancy diagnosis $60 \mathrm{~d}$ after $\mathrm{AI}$ ) given a set of fixed factors $\mathrm{Zi}$, the random effect of herd $\mu$, and the set of multiplicative slopes $\beta \mathrm{i}$, indicating the rate of change in the logit function for changes in values of $\mathrm{x}$, and a scale parameter $\sigma^{2}$ applied to correct for potential overdispersion (SE are multiplied by $\sigma$, making the confidence intervals wider).

Reproductive Index 1. The associations between each of the predictors were tested, and variables with variance inflation factor $>3$ or with odds ratio $>7$ were not included in the same model for RI1 (i.e., parity number and age). This was accomplished via testing of multivariate models, including the fixed effects of all predictors with $P \leq 0.05$ from the univariable models and the random effect of herd. Explanatory variables were subsequently removed via a backward-elimination process based on the highest $P$-value, until all remaining variables had $P \leq 0.05$. 
The final model for RI1 included the random effect of herd and a complement of significant fixed effects as explanatory variables influencing pregnancy outcome: (1) retained fetal membranes, (2) metritis, (3) clinical endometritis, (4) lameness at 35 DIM, (5) resumption of ovulation by 50 DIM, (6) season of calving, and (7) parity number. To assess the model fitness and the overall predictability of the final statistical model, receiver operating characteristic curve analyses were performed, using the predicted probability estimates (RI) and the dichotomous variable pregnancy. Values for the RI ranged from 0.10 to 0.49 for AI.

Reproductive Index 2. Potential significant effects were tested initially via univariate analysis. Effects with $P<0.05$ were evaluated in the multivariate analysis, and the final model was determined through backward elimination, considering potentially significant interactions. The final model for RI2 included a complement of significant fixed effects and interactions as explanatory variables influencing a pregnancy outcome: (1) retained fetal membranes, (2) subclinical ketosis, (3) metritis, (4) clinical endometritis (5) BCS at 40 DIM,
(6) resumption of ovulation by 50 DIM, (7) mastitis, (8) milk yield at the first milk test after calving, (9) parity number, (10) region (11) interaction effect of resumption of ovulation by 50 DIM $\times$ region, (12) interaction of mastitis $\times$ region, and (13) interaction milk yield at the first milk test after calving $\times$ parity number. For RI2, herd and season of calving were intentionally excluded with the purpose of subsequently comparing cows within herd and season of calving.

\section{Outcome Variables of Interest}

Reproductive outcome variables for index assessment were calving to first service interval (CFSI), defined as the number of days between parturition and the subsequent first AI; calving to conception interval (CCI), defined as the number of days between parturition and the AI that resulted in a pregnancy (confirmed at the pregnancy diagnosis $60 \mathrm{~d}$ after $\mathrm{AI}$ ); and services per conception, defined as the number of AI that a cow required to conceive during the current lactation. In addition, pregnancy per AI at first and second AI, as

Table 1. Summary of frequencies of health-related conditions, average BCS, average milk yield at 90 DIM, and reproductive and survival variables by geographic region

\begin{tabular}{|c|c|c|c|c|}
\hline \multirow[b]{2}{*}{ Item } & \multicolumn{4}{|c|}{ Geographic region (n) } \\
\hline & $\begin{array}{c}\text { Midwest } \\
(5,189)\end{array}$ & $\begin{array}{c}\text { Northeast } \\
(2,635)\end{array}$ & $\begin{array}{c}\text { Southeast } \\
(1,183)\end{array}$ & $\begin{array}{c}\text { Southwest } \\
(2,726)\end{array}$ \\
\hline \multicolumn{5}{|c|}{ Health-related conditions $(\% \pm \mathrm{SE})$} \\
\hline Dystocia & $16.9 \pm 0.4$ & $11.8 \pm 0.6$ & $11.7 \pm 0.1$ & $12.5 \pm 0.9$ \\
\hline Stillbirth & $6.42 \pm 0.3$ & $4.23 \pm 0.4$ & $3.13 \pm 0.6$ & $4.26 \pm 0.4$ \\
\hline Twins & $5.49 \pm 0.2$ & $3.15 \pm 0.4$ & $2.37 \pm 0.5$ & $3.41 \pm 0.3$ \\
\hline Subclinical ketosis ${ }^{2}$ & $20.4 \pm 0.6$ & $30.2 \pm 0.8$ & $22.5 \pm 0.9$ & $21.6 \pm 0.8$ \\
\hline Left displaced abomasum & $2.60 \pm 0.2$ & $1.98 \pm 0.3$ & $4.90 \pm 0.4$ & $0.22 \pm 0.3$ \\
\hline Mastitis & $24.4 \pm 0.4$ & $24.0 \pm 0.6$ & $32.9 \pm 0.9$ & $26.4 \pm 0.6$ \\
\hline Clinical endometritis ${ }^{3}$ & $24.4 \pm 0.6$ & $24.0 \pm 0.8$ & $32.9 \pm 0.9$ & $26.4 \pm 0.8$ \\
\hline Lameness $^{4}$ & $13.9 \pm 0.4$ & $10.7 \pm 0.7$ & $12.6 \pm 0.9$ & $9.30 \pm 0.6$ \\
\hline Pneumonia & $1.16 \pm 0.2$ & $1.41 \pm 0.3$ & $8.50 \pm 0.4$ & $3.48 \pm 0.2$ \\
\hline \multicolumn{5}{|c|}{ Performance variable (mean $\pm \mathrm{SE}$ ) } \\
\hline Pregnant AI2 & $37.4 \pm 0.9$ & $35.7 \pm 0.9$ & $36.8 \pm 0.017$ & $38.3 \pm 0.9$ \\
\hline Pregnancy loss AI1 & $7.43 \pm 0.7$ & $9.44 \pm 0.9$ & $12.0 \pm 0.016$ & $14.9 \pm 0.9$ \\
\hline Pregnancy loss AI2 & $7.60 \pm 0.8$ & $8.11 \pm 0.8$ & $8.42 \pm 0.017$ & $10.7 \pm 0.9$ \\
\hline Left herd ${ }^{8}$ & $18.5 \pm 0.6$ & $22.4 \pm 0.8$ & $15.4 \pm 0.012$ & $18.9 \pm 0.8$ \\
\hline
\end{tabular}

\footnotetext{
${ }^{1}$ Assessed at $7 \pm 3$ DIM; mucus score 5 .

${ }^{2}$ Assessed at $7 \pm 3$ DIM; serum BHB $>1.0 \mathrm{mmol} / \mathrm{L}$.

${ }^{3}$ Assessed at $28 \pm 7$ DIM; mucus score $>2$.

${ }^{4}$ Assessed at $35 \pm 3$ DIM; score $>2$.

${ }^{5} \mathrm{BCS}$ at calving.

${ }^{6} \mathrm{BCS}$ at 40 DIM.

${ }^{7}$ Average daily milk yield in the first 90 DIM.

${ }^{8}$ Combined death and live culling before 305 DIM.
} 
well as pregnancy loss between 32 and $60 \mathrm{~d}$ after AI1 and second AI postpartum (AI2), were evaluated.

Production variables included average milk yield until 90 DIM and 305 DIM and the difference in milk yield between the third monthly TDM (TDM3) and the second monthly TDM (TDM2), defined as TDM3_2. The outcome variable "left herd" was defined as the departure of a cow from the herd due to live culling or death until 305 DIM.

\section{Statistical Analysis}

To facilitate the analyses, the resulting RI values were categorized as low (LRI) for cows in the lowest quartile (RI1 $<0.26$ and RI $<0.28$ ); medium (MRI; $0.26 \geq \mathrm{RI} 1 \leq 0.39$, and $0.28 \geq \mathrm{RI} 2 \leq 0.40$ ) for cows within the interquartile range, and high (HRI; RI1 > 0.39 and RI2 > 0.40) for cows in the uppermost quartile. Logistic regression (PROC GLIMMIX, SAS release 9.2; SAS Institute Inc., Cary, NC) was used for analysis of binary outcome variables, whereas continuous variables were evaluated using linear mixed models (PROC MIXED). Time-to-event analyses (Kaplan-Meier method) were used to evaluate differences in DIM for first AI (considering spontaneous vs. synchronized estrus), conception, and survival (PROC LIFETEST). Hazard ratios by RI category were calculated using Cox proportional hazards models (PROC PHREG). Univariate analyses were considered to test the inclusion of each explanatory variable in the final models. Effects with a $P$-value $<0.20$ were included in the initial multivariate analysis, and the final models were tested through a backward-elimination procedure. The significance level for inclusion in the final model was set at $P<0.10$ to account for potential confounders affecting both the response and the predictors. Reproductive index category was forced into the final models, and interactions between the effect of RI and significant covariates were considered.

\section{RESULTS}

\section{Reproductive Index 1 for Pregnancy at Al1}

Cows leaving the herd (live culling or death) and cows that were determined as "do not breed" by farm management before an outcome for AI1 was established were excluded from the analyses. After edits, a total of 10,734 cows were included in the final RI1 calculation, with 2,152, 5,226, and 3,356 animals in LRI1, MRI1, and HRI1 categories, respectively. Values for RI1, representing a predicted probability that a cow will become pregnant, ranged from 0.10 to 0.49 with mean 0.33 .
Least squares means for health-related conditions, average body condition score, and average milk yield at 90 DIM by category of RI1 are reported in Table 2 . Regarding reproductive outcomes, least squares means for CFSI and CCI, from the models including the fixed effects of parity and season and random effects of herd and region, were greatest for cows in LRI1, followed by MRI1 and HRI1 categories.

For cows in LRI1, MRI1, and HRI1 categories, averages (SE) of CFSI were $76.0(0.35) \mathrm{d}, 74.0(0.22) \mathrm{d}$, and $73.3(0.27) \mathrm{d}$, respectively, with all pairwise comparisons resulting in $P<0.001$. Calving to conception interval values were $148(1.49)$ d, 132 (0.65) d, and 119 (1.20) d for cows in LRI1, MRI1, and HRI1 categories, respectively, with all pairwise comparisons resulting in $P<0.001$ (Figure 1). Similarly, the number of services per conception were $2.66(0.04), 2.37(0.03)$, and 2.15 (0.03) for LRI1, MRI1, and HRI1, respectively $(P<$ $0.0001)$.

The proportions of pregnant cows at first and second AI increased from LRI1 to the MRI1 and HRI1 categories $(P<0.0001$; Figure 2). Pregnancy losses following first AI were smaller for cows in HRI1, followed by MRI1, and LRI1 $(P<0.0001)$, and a similar trend was observed for pregnancy loss following second AI $(P=$ 0.002 ; Figure 3 ). The time to event analyses indicated that the hazard ratios for pregnancy, representing the relative risk for pregnancy between 2 RI categories, were 0.54 and 0.75 for LRI1 and MRI1 relative to HRI1 $(P<0.001)$. Survival curves for the time from calving to conception are presented in Figure 4.

Results from the multivariate logistic regression analyses indicated that cows in the LRI1 and MRI1 categories had lower odds of conceiving at first and second AI than did cows in HRI1 (Table 3). Similarly, cows in the LRI1 and MRI1 categories had greater odds of losing their pregnancy after first and second AI than did HRI1 cows (Table 3).

Least squares means (SE) for M90 were 37.5 (0.19) $\mathrm{kg}, 38.5(0.12) \mathrm{kg}$, and $38.7(0.14) \mathrm{kg}$ for LRI1, MLI, and HRI1, respectively. Significant differences in M90 were determined for LRI1 compared with MRI1 $(P$ $<0.0001)$ and for LRI1 compared with HRI1 $(P<$ 0.0001; Table 2).

Least squares means (SE) for TDM3_2 were 2.28 $(0.33) \mathrm{kg}, 1.08(0.20) \mathrm{kg}$, and $0.83(0.25) \mathrm{kg}$ in LRI1, MRI1, and HRI1, respectively, with significant differences determined for LRI1 compared with MRI1 $(P$ $=0.004)$ and LRI1 compared with HRI1 $(P=0.002)$. Least squares means (SE) for days survived were 269.8 (1.41) d, 280.3 (0.89) d, and 285.4 (1.1) d for LRI1, MLI, and HRI1, respectively. Significant differences in days survived were determined for LRI1 compared with MRI1 $(P<0.0001)$, for LRI1 compared with HRI1 $(P$ 
$<0.0001)$, and for MRI1 compared with HRI1 $(P=$ 0.001). The odds (95\% CI) of leaving the herd (death or live culling) at 305 DIM for cows in LRI1 and MRI1 were 1.87 (1.60 to 2.17$)$ and 1.29 (1.13 to 1.47$)$ times the odds of cows in HRI1 $(P<0.0001)$. Similarly, the hazard ratios for leaving the herd were 2.28 and 1.54 for LRI1 and MRI1 relative to HRI1 $(P<0.001)$. Survival curves for the interval from calving to death or live culling are presented in Figure 4.

\section{Reproductive Index 2 for Pregnancy at Al1}

After edits, 10,150 cows were included in the final index calculation, with 2,137, 5,250, and 2,763 animals in the LRI2, MRI2, and HRI2 categories, respectively. For RI2 the range was 0.03 to 0.55 , with a mean of 0.33 .

Least squares means for health-related conditions, average body condition score, and average milk yield at 90 DIM by category of RI2 are provided in Table

Table 2. Least squares means for health-related conditions, average BCS, and average milk yield at 90 DIM by category of reproductive indices $(\mathrm{RI})^{1}$

\begin{tabular}{|c|c|c|c|}
\hline \multirow[b]{2}{*}{ Item } & \multicolumn{3}{|c|}{ RI category } \\
\hline & Low RI & Medium RI & High RI \\
\hline \multicolumn{4}{|l|}{ RI1 } \\
\hline \multicolumn{4}{|c|}{ Health-related conditions $(\% \pm \mathrm{SE})$} \\
\hline Dystocia & $16.2^{\mathrm{a}} \pm 0.8$ & $14.6^{\mathrm{a}} \pm 0.5$ & $10.8^{\mathrm{b}} \pm 0.6$ \\
\hline Stillbirth & $6.40^{\mathrm{a}} \pm 0.5$ & $4.99^{\mathrm{b}} \pm 0.3$ & $3.26^{\mathrm{c}} \pm 0.4$ \\
\hline Twins & $7.48^{\mathrm{a}} \pm 0.4$ & $2.35^{\mathrm{b}} \pm 0.3$ & $1.20^{\mathrm{c}} \pm 0.3$ \\
\hline Retained fetal membranes & $16.5^{\mathrm{a}} \pm 0.5$ & $6.51^{\mathrm{b}} \pm 0.4$ & $1.12^{\mathrm{c}} \pm 0.4$ \\
\hline Metritis $^{2}$ & $54.4^{\mathrm{a}} \pm 0.9$ & $32.0^{\mathrm{b}} \pm 0.6$ & $13.9^{\mathrm{b}} \pm 0.7$ \\
\hline Subclinical ketosis $^{3}$ & $30.0^{\mathrm{a}} \pm 0.9$ & $21.9^{\mathrm{b}} \pm 0.6$ & $20.0^{\mathrm{c}} \pm 0.7$ \\
\hline Left displaced abomasum & $3.79^{\mathrm{a}} \pm 0.3$ & $1.20^{\mathrm{b}} \pm 0.2$ & $1.20^{\mathrm{b}} \pm 0.2$ \\
\hline Mastitis & $14.5^{\mathrm{a}} \pm 0.7$ & $12.4^{\mathrm{b}} \pm 0.4$ & $13.3^{\mathrm{b}} \pm 0.6$ \\
\hline Clinical endometritis ${ }^{4}$ & $66.5^{\mathrm{a}} \pm 0.8$ & $33.8^{\mathrm{b}} \pm 0.5$ & $3.00^{\mathrm{c}} \pm 0.6$ \\
\hline Lameness ${ }^{5}$ & $21.1^{\mathrm{a}} \pm 0.7$ & $13.3^{\mathrm{b}} \pm 0.4$ & $1.00^{\mathrm{c}} \pm 0.6$ \\
\hline Pneumonia & $4.30^{\mathrm{a}} \pm 0.3$ & $3.30^{\mathrm{b}} \pm 0.2$ & $2.30^{\mathrm{c}} \pm 0.2$ \\
\hline \multicolumn{4}{|c|}{ Performance variable $($ mean $\pm \mathrm{SE})$} \\
\hline BCS $0^{6}$ & $3.08^{\mathrm{a}} \pm 0.009$ & $3.16^{\mathrm{b}} \pm 0.006$ & $3.23^{\mathrm{c}} \pm 0.007$ \\
\hline BCS $40^{7}$ & $2.88^{\mathrm{a}} \pm 0.009$ & $2.96^{\mathrm{b}} \pm 0.006$ & $3.05^{\mathrm{c}} \pm 0.007$ \\
\hline M90 ${ }^{8}$ & $37.5^{\mathrm{a}} \pm 0.200$ & $38.5^{\mathrm{b}} \pm 0.130$ & $38.7^{\mathrm{b}} \pm 0.160$ \\
\hline \multicolumn{4}{|l|}{ RI2 } \\
\hline \multicolumn{4}{|c|}{ Health-related conditions $(\% \pm \mathrm{SE})$} \\
\hline Dystocia & $13.9^{\mathrm{a}} \pm 0.8$ & $13.7^{\mathrm{a}} \pm 0.5$ & $12.0^{\mathrm{b}} \pm 0.8$ \\
\hline Stillbirth & $6.15^{\mathrm{a}} \pm 0.5$ & $4.20^{\mathrm{b}} \pm 0.3$ & $2.90^{\mathrm{c}} \pm 0.5$ \\
\hline Twins & $6.10^{\mathrm{a}} \pm 0.4$ & $2.26^{\mathrm{b}} \pm 0.3$ & $1.10^{\mathrm{b}} \pm 0.4$ \\
\hline Retained fetal membranes & $15.5^{\mathrm{a}} \pm 0.5$ & $5.10^{\mathrm{b}} \pm 0.3$ & $1.15^{\mathrm{c}} \pm 0.5$ \\
\hline Metritis & $41.9^{\mathrm{a}} \pm 0.9$ & $31.9^{\mathrm{b}} \pm 0.6$ & $11.9^{\mathrm{c}} \pm 0.9$ \\
\hline Subclinical ketosis & $30.2^{\mathrm{a}} \pm 0.9$ & $24.7^{\mathrm{b}} \pm 0.6$ & $10.0^{\mathrm{c}} \pm 0.9$ \\
\hline Left displaced abomasum & $3.55^{\mathrm{a}} \pm 0.2$ & $1.10^{\mathrm{b}} \pm 0.2$ & $0.08^{\mathrm{c}} \pm 0.3$ \\
\hline Mastitis & $17.1^{\mathrm{a}} \pm 0.7$ & $8.10^{\mathrm{b}} \pm 0.5$ & $17.6^{\mathrm{a}} \pm 0.7$ \\
\hline Clinical endometritis & $47.7^{\mathrm{a}} \pm 0.9$ & $28.5^{\mathrm{b}} \pm 0.6$ & $4.00^{\mathrm{c}} \pm 0.9$ \\
\hline Lameness & $10.9^{\mathrm{a}} \pm 0.7$ & $9.80^{\mathrm{a}} \pm 0.5$ & $10.8^{\mathrm{a}} \pm 0.7$ \\
\hline Pneumonia & $3.00^{\mathrm{a}} \pm 0.3$ & $2.20^{\mathrm{a}} \pm 0.2$ & $2.15^{\mathrm{a}} \pm 0.3$ \\
\hline \multicolumn{4}{|c|}{ Performance variable: Mean $\pm \mathrm{SE}$} \\
\hline BCS 0 & $3.12^{\mathrm{a}} \pm 0.10$ & $3.16^{\mathrm{b}} \pm 0.007$ & $3.28^{\mathrm{c}} \pm 0.009$ \\
\hline BCS 40 & $2.90^{\mathrm{a}} \pm 0.09$ & $2.95^{\mathrm{b}} \pm 0.006$ & $3.14^{\mathrm{c}} \pm 0.009$ \\
\hline M90 & $38.0^{\mathrm{ab}} \pm 0.19$ & $37.9^{\mathrm{a}} \pm 0.130$ & $39.2^{\mathrm{b}} \pm 0.190$ \\
\hline
\end{tabular}

${ }^{\mathrm{a}-\mathrm{c}}$ Different letters indicate significant differences between RI categories $(P<0.01)$.

${ }^{1}$ Low $\mathrm{RI}=$ cows in the lowest quartile $(\mathrm{RI} 1<0.26$ and RI $<0.28)$; medium RI = cows within the interquartile range $(0.26 \geq \mathrm{RI} 1 \leq 0.39$ and $0.28 \geq \mathrm{RI} 2 \leq 0.40)$; high $\mathrm{RI}=$ cows in the top quartile $(\mathrm{RI} 1>0.39$ and RI $2>$ $0.40)$. The final model included parity and season of calving as fixed effects and herd and region as random effects.

${ }^{2}$ Assessed at $7 \pm 3$ DIM; mucus score 5 .

${ }^{3}$ Assessed at $7 \pm 3$ DIM; serum BHB $>1.0 \mathrm{mmol} / \mathrm{L}$.

${ }^{4}$ Assessed at $28 \pm 7$ DIM; mucus score $>2$.

${ }^{5}$ Assessed at $35 \pm 3$ DIM; score $>2$.

${ }^{6} \mathrm{BCS}$ at calving.

${ }^{7} \mathrm{BCS}$ at 40 DIM.

${ }^{8}$ Average daily milk yield in the first 90 DIM. 
2. Least squares means for CFSI and CCI, from the models including the fixed effects of parity and season and random effects of herd and region, are depicted in Figure 1. For cows in LRI2, mean (SE) CFSI was longer [76.1 $(0.35) \mathrm{d}]$ than that of cows in MRI2 [73.4 $(0.22) \mathrm{d}$; $P<0.001]$ and cows in HRI2 [74.4 (0.22) d; $P<0.001$. No difference was detected between MRI2 and HRI2. Calving to conception interval values were 153 (1.49) $\mathrm{d}, 129(0.95) \mathrm{d}$, and 119 (1.31) d for cows in LRI2, MRI2, and HRI2 categories, respectively, with all pairwise comparisons resulting in $P<0.001$. Similarly, the number of services per conception were progressively lower for LRI2, MRI2, and HRI2, with 2.74 (0.04), 2.35 (0.02), and $2.06(0.03)$, respectively $(P<0.0001$ for all pairwise comparisons).
The proportions of pregnant cows at first AI increased from LRI2 to the MRI2 and HRI2 categories $(P<0.0001)$. For pregnancy at AI2, differences were determined only for LRI2 versus MRI2 and for LRI2 versus HRI2 (Figure 2). Pregnancy loss values following first AI were smaller for cows in HRI2, followed by MRI2 and LRI2 $(P<0.0001)$, whereas pregnancy loss following second AI was smaller for HRI2 than for LRI2 and MRI2 $(P<0.0001$; Figure 3$)$. The time to event analyses indicated that the hazard ratios for pregnancy, representing the relative risk for pregnancy between 2 RI categories, were 0.54 and 0.82 for LRI2 and MRI2 relative to HRI2 $(P<0.001 ;$ Figure 4$)$.

Results from the multivariable logistic regression analyses indicated that cows in the LRI2 and MRI2

$\square \mathrm{LRI} \square \mathrm{MRI} \square \mathrm{HRI}$
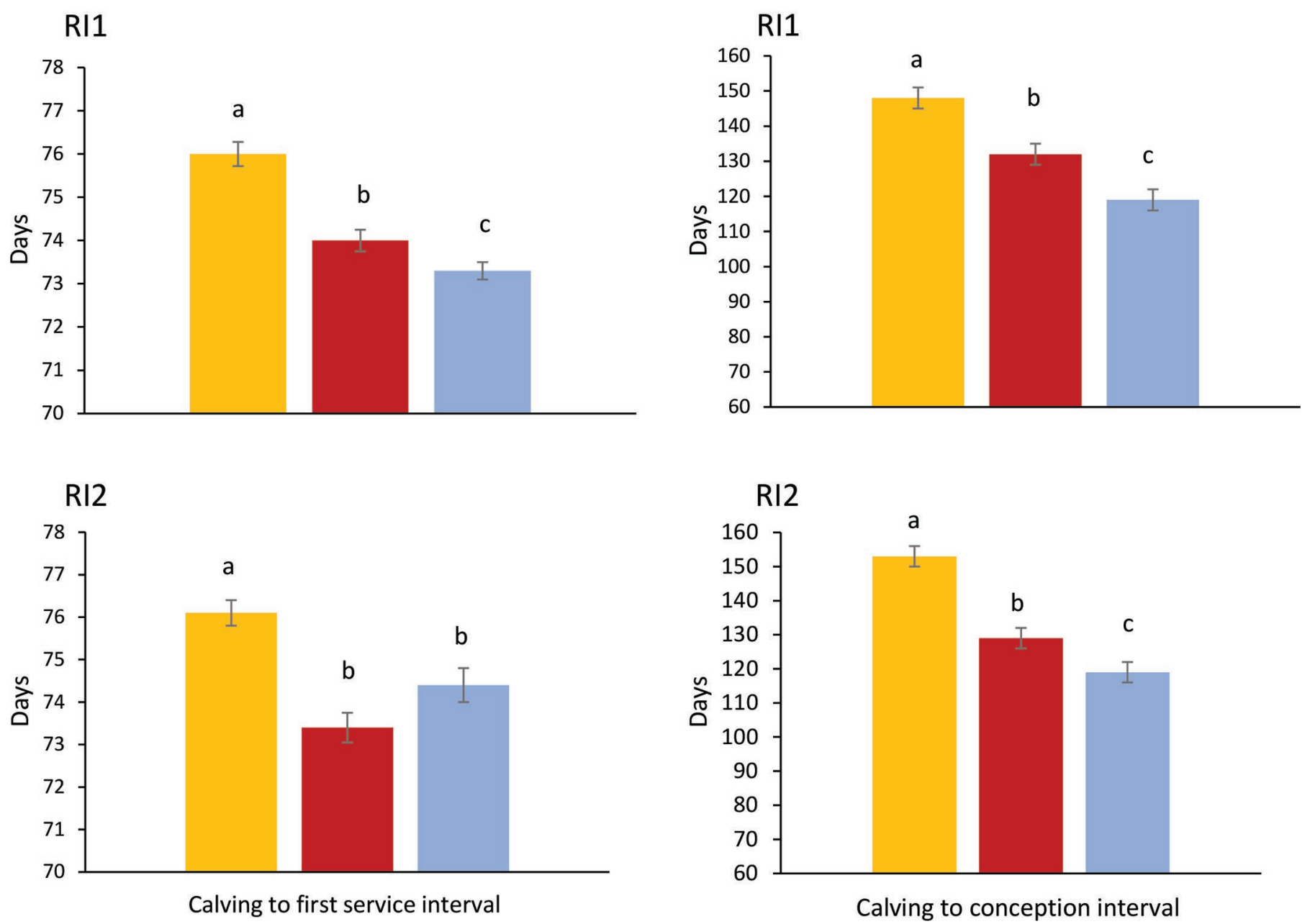

Figure 1. Least squares means $( \pm \mathrm{SEM})$ for calving to first service and calving to conception intervals for different categories of the reproductive indices $(\mathrm{RI})$. LRI $=$ cows in the lowest quartile $(\mathrm{RI} 1<0.26$ and $\mathrm{RI} 2<0.28)$; MRI $=$ cows within the interquartile range $(0.26 \geq \mathrm{RI}$ $\leq 0.39$ and $0.28>$ RI $\leq 0.40)$; HRI $=$ cows in the top quartile $(\mathrm{RI} 1>0.39$ and RI2 $>0.40)$. The final model included parity and season of calving as fixed effects and herd and region as random effects. Different lowercase letters $(\mathrm{a}-\mathrm{c})$ indicate significant differences between RI categories $(P<0.0001)$. 


\section{RI1}
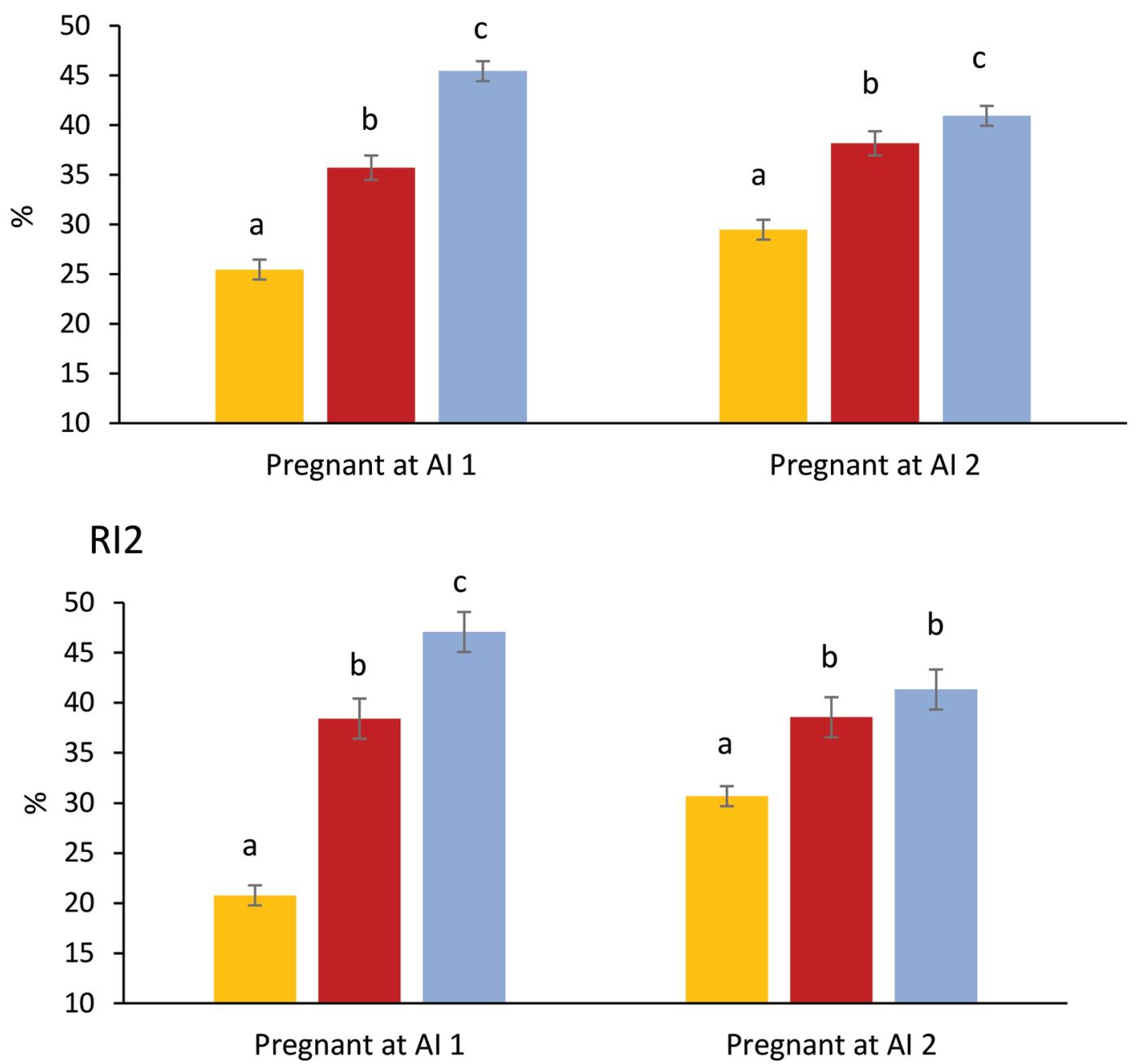

Figure 2. Least squares means $( \pm \mathrm{SEM})$ for pregnancy at first $\mathrm{AI}$ at different categories of the reproductive indices $(\mathrm{RI})$. LRI $=$ cows in the lowest quartile $(\mathrm{RI} 1<0.26$ and $\mathrm{RI} 2<0.28) ; \mathrm{MRI}=$ cows within the interquartile range $(0.26 \geq \mathrm{RI} 1 \leq 0.39$ and $0.28 \geq \mathrm{RI} 2 \leq 0.40) ; \mathrm{HRI}=$ cows in the top quartile (RI1 $>0.39$ and RI2 $>0.40$ ). The final model included parity and season of calving as fixed effects and herd and region as random effects. Different lowercase letters $(\mathrm{a}-\mathrm{c})$ indicate significant differences between RI categories $(P<0.001)$.

categories had lower odds of conceiving at first and second AI than did cows in HRI2 (Table 3). Similarly, cows in the LRI2 and MRI2 categories had greater odds of losing their pregnancy after first and second AI than did HRI2 cows (Table 3).

Least squares means (SE) for M90 were 38.0 (0.17) $\mathrm{kg}, 37.9(0.12) \mathrm{kg}$, and $39.2(0.15) \mathrm{kg}$ for LRI2, MRI2, and HRI2, respectively. Significant differences in M90 were detected only for MRI2 versus HRI2 $(P<0.0001$; Table 2). Least squares means (SE) for TDM3_2 were $2.58(0.29) \mathrm{kg}, 0.93(0.21) \mathrm{kg}$, and $1.34(0.27) \mathrm{kg}$, with significant differences determined for LRI2 versus MRI2 $(P<0.0001)$ and LRI2 versus HRI2 $(P=0.006)$. Least squares means (SE) for days survived were 272.3 (1.33) d, $278.2(0.84) d$, and 283.1 (1.17) d for LRI2, MLI, and HRI2, respectively. Significant differences in days survived were determined for LRI2 versus MRI2 $(P=$ $0.0008)$ and for LRI2 versus HRI2 $(P=0.0003)$. The odds $(95 \% \mathrm{CI})$ of leaving the herd (death or live culling) at 305 DIM for cows in LRI2 and MRI2 were 1.49 (1.28 to 1.74$)$ and 0.91 (0.78 to 1.06 ) times the odds of cows in HRI2 $(P<0.0001)$. Similarly, the hazard ratios for leaving the herd were 1.60 and 1.21 for LRI2 and MRI2 relative to HRI2 $(P<0.001)$. Survival curves for the interval from calving to death or live culling are presented in Figure 4. 


\section{DISCUSSION}

This study is part of a research effort investigating potential associations between genomic variation and fertility of Holstein cows. We developed 2 indices as a tool for identifying cows within high- and low-fertility groups for genomic testing in multiple herds. The ability of both indices for ranking cows for fertility was tested using a categorization of the index values and variables assessing reproductive performance. In addition, the indices were contrasted with average milk production until 90 DIM and the ability of cows to remain in the herd for the complete lactation.
From the management perspective, combining multiple postpartum events occurring early in lactation into a single index provides dairy producers with simple information to make decisions, such as delaying breeding or selecting individuals for future culling, based on potential fertility outcomes. On the other hand, the use of an index that combines multiple variables affecting fertility for the selection of individuals for genomic testing allows for the analysis of interrelated factors that could also be associated at the genomic level.

The association between events taking place in the peripartum and the subsequent fertility and performance of dairy cows has been reported widely (Bicalho et al.,

\section{$\mathrm{LRI} \square \mathrm{MRI} \backsim \mathrm{HRI}$}

\section{RI1}
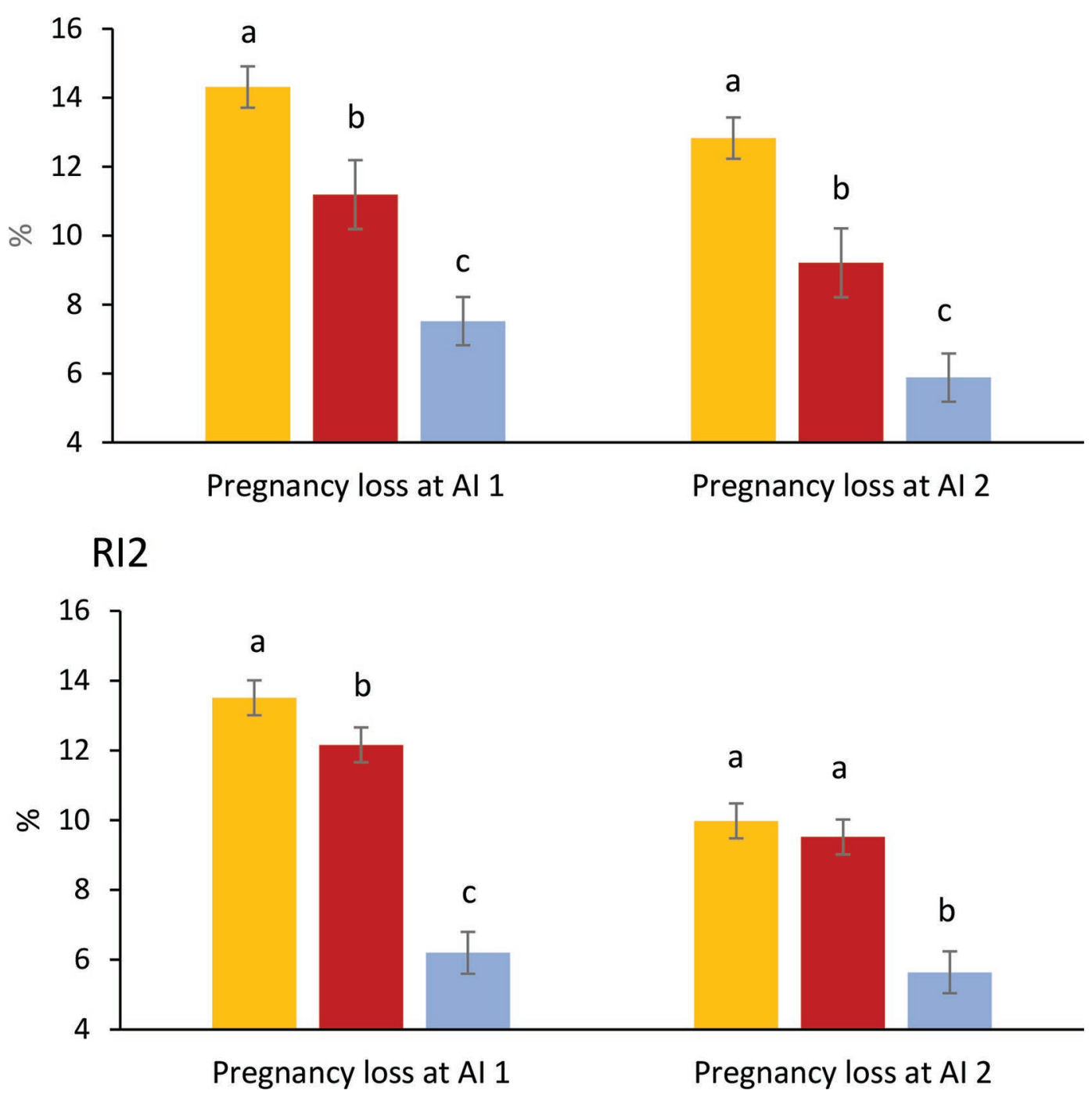

Figure 3. Least squares means $( \pm \mathrm{SEM})$ for pregnancy loss at second AI at different categories of the reproductive indices $(\mathrm{RI}) . \mathrm{LRI}=$ cows in the lowest quartile (RI1 $<0.26$ and RI $2<0.28) ; \mathrm{MRI}=$ cows within the interquartile range $(0.26 \geq \mathrm{RI} 1 \leq 0.39$ and $0.28 \geq \mathrm{RI} 2 \leq 0.40) ; \mathrm{HRI}$ $=$ cows in the top quartile (RI1 $>0.39$ and RI $>0.40)$. The final model included parity and season of calving as fixed effects and herd and region as random effects. Different lowercase letters $(\mathrm{a}-\mathrm{c})$ indicate significant differences between RI categories $(P<0.05)$. 
2007a; Ribeiro et al., 2016; Carvalho et al., 2019). Data presented in Table 2 aligns with these reported associations, whereby greater levels of disease frequency occur for cows in the LRI category, followed by MRI. In both indices, we found consistency in HRI cows for lower disease presentation, as well as greater BCS at calving and at 40 DIM. The differences in incidence of retained fetal membranes, metritis, and clinical endometritis among RI categories are clearly indicative of their consistent effects on pregnancy at first AI.

Further investigation should be performed, comparing the magnitudes of the associations with subsequent fertility among the RI presented here with those of specific reproductive disorders. For example, in this population, the odds ( $95 \% \mathrm{CI}$ ) of pregnancy at AI1 for cows with metritis were 0.75 (0.67 to 0.83$)$ times the odds of pregnancy at AI1 for unaffected cows.

Some investigators have proposed methodologies to evaluate the transition period at the herd level, measuring multiple combinations of events occurring in early lactation that influence performance (Dechow and Goodling, 2008). Others have developed indices that consider individual animals, calculating differences between real and predicted milk production for the first test day in the new lactation (Nordlund and Cook, 2004; Nordlund, 2006).

In this study, 2 RI were developed, with the goal of assessing the ability of individual Holstein cows to maintain adequate fertility while coping with earlylactation challenges. Therefore, the outcome variable

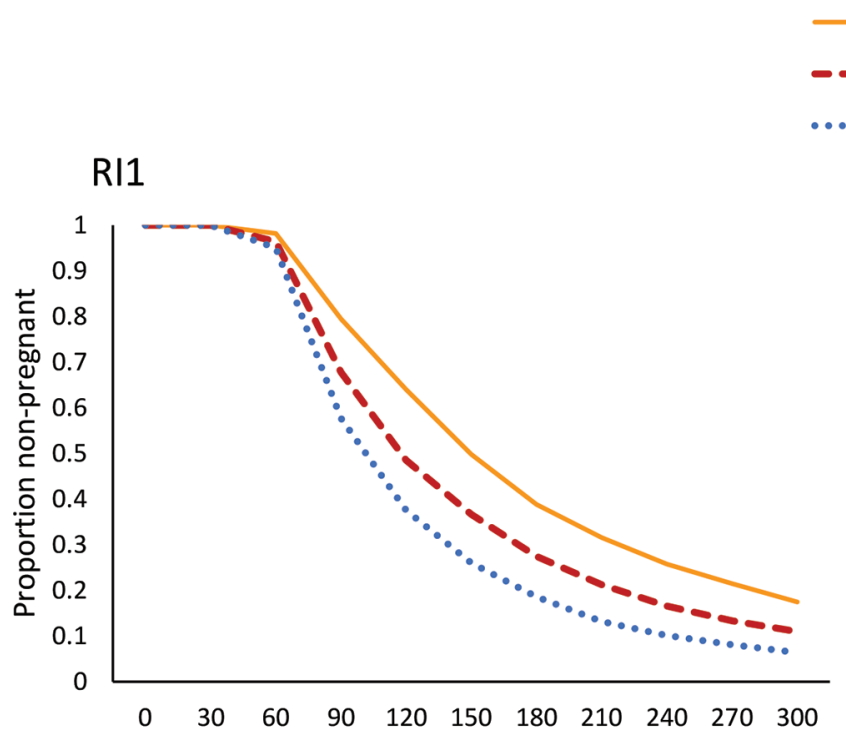

LRI

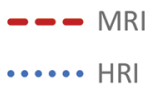

HRI

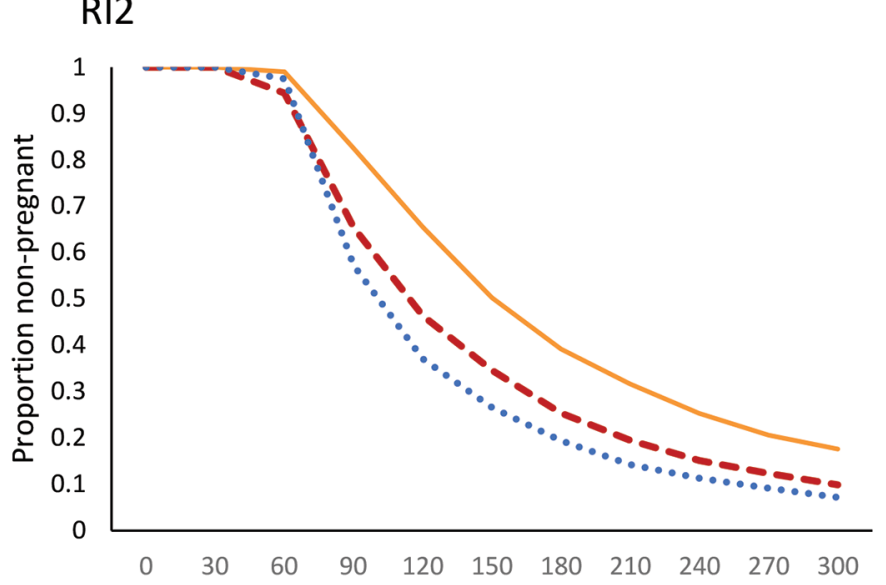

\section{RI1}
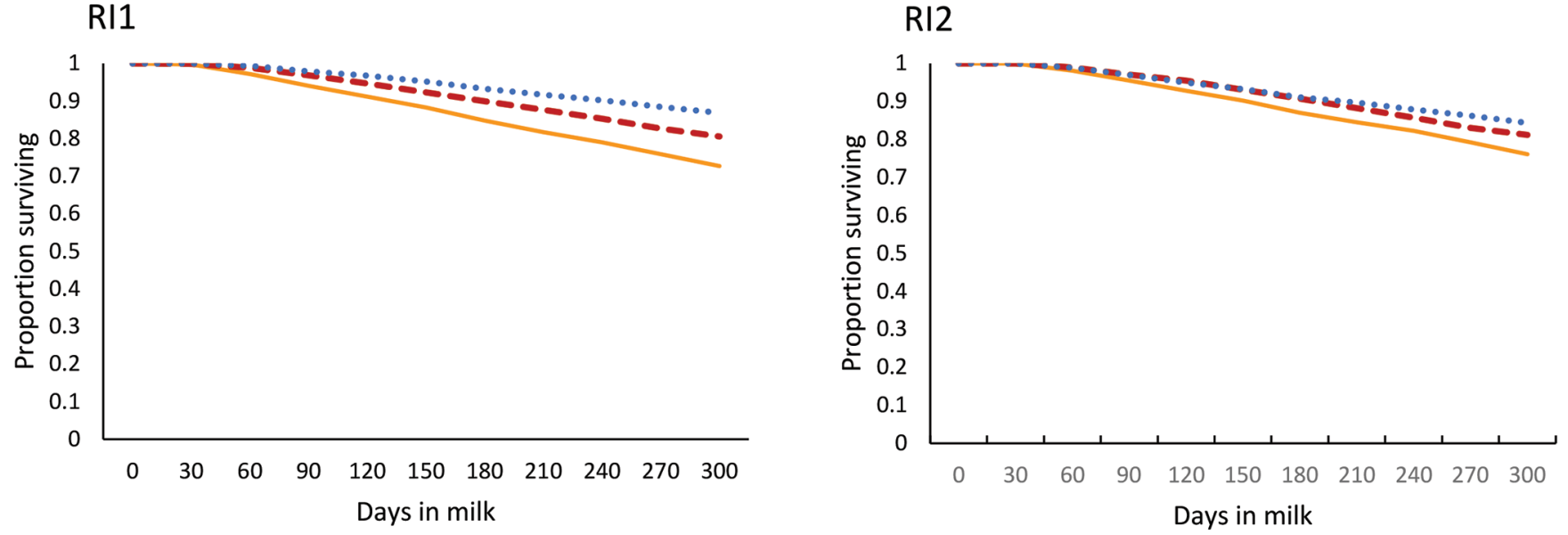

Figure 4. Kaplan-Meier survival curves for the interval from calving to conception (top) and the proportion of cows remaining in the herd until 305 DIM (bottom) by different categories of the reproductive indices (RI1 on the left; RI2 on the right). LRI (orange solid line) $=$ cows in the lowest quartile (RI1 $<0.26$ and RI $<0.28)$; MRI (red dashed line) $=$ cows within the interquartile range $(0.26 \geq$ RI1 $\leq 0.39$ and $0.28 \geq$ $\mathrm{RI} 2 \leq 0.40) ; \mathrm{HRI}$ (blue dotted line) = cows in the top quartile (RI1 > 0.39 and RI2 $>0.40$ ). 
considered in the modeling process was pregnancy at first AI, as indicated by confirmatory diagnosis at 60 d after breeding, to include the period of significant embryo mortality (32 to $60 \mathrm{~d}$ after conception).

The statistical modeling of each index was performed following slightly different approaches and resulting in different RI ranges and rankings of cows. Subsequently, we tested the associations among the resulting RI (RI1 and RI2) and multiple fertility variables in a large multistate population of Holstein cows. In addition, the associations among the indices and milk yield and cow survival were explored. A singular strength of this study was the prospective approach for data collection, using standardized definitions for all health conditions and reproductive outcomes (resumption of ovarian cyclicity and assessment of pregnancy loss). This feature contrasts with the retrospective nature of data in some reports, which mostly used farm records (Nordlund and Cook, 2004; Lukas et al., 2015). Nonetheless, if these indices were to be applied in the field, within-farm inconsistencies in the assessment of some of the variables included in the indices could be a disadvantage that would deserve consideration.

The ranges of values for both RI, representing a calculated probability that a cow will become pregnant at first AI, were similar (RI1 from 0.10 to 0.49 , and RI2 from 0.03 to 0.55 ), and, as expected, we found consistent agreement between the categories of the RI1 and RI2 indices and the fertility variables analyzed in this study. As evidenced in Figures 1 and 2, categories of RI1 and RI2 were significantly associated with the time from calving to first AI, the time to conception, and the proportions of cows that conceived at first and second AI.

Several reproductive health conditions were considered as potential predictive variables in the analyses leading to the RI. The detrimental effect of suboptimal postpartum health on fertility is well recognized (Gilbert, 2019), and both indices included different combinations of uterine and metabolic diseases in their models. However, reproductive events were emphasized in RI1, whereas RI2 considered other health disorders, milk yield, the effect of geographic region (instead of herd), and interaction terms.

Occurrence of retained fetal membranes, metritis, and clinical endometritis were reproductive events shared by both indices, which agrees with the widely recognized negative influence of uterine disorders on fertility (Dubuc et al., 2011; Gilbert, 2019). Bacteria and inflammation from the uterus affect ovarian follicular activity in early lactation, which compromises resumption of ovulation (Sheldon et al., 2002). In addition, uterine inflammation disturbs the endometrium and the uterine glands, which are crucial for establishment and maintenance of pregnancy (Ribeiro et al., 2013). Moreover, the size of early conceptuses and the concentration of interferon- $\tau$ is compromised in cows affected by disease before AI (Ribeiro et al., 2016).

The importance of retention of fetal membranes on subsequent reproductive diseases and impaired fertility was reported by Gröhn and Rajala-Schultz (2000), who showed that cows experiencing retained fetal membranes had $14 \%$ lower conception rates than unaffected cows. In addition, cows with retained fetal membranes were at higher risk than cows without for developing other clinical diseases or being removed from the herd early in lactation (Gröhn et al., 1998; Dubuc et al., 2010). The effect of metritis on fertility is characterized by extended postpartum days to first service, reduced conception rates at first service, and extended postpartum days to conception and increased risk for culling (Fourichon et al., 2000; Gröhn et al., 2003). Meanwhile,

Table 3. Odds ratios (95\% CI in parentheses) for multiple fertility outcomes by reproductive index (RI) category $^{1}$

\begin{tabular}{lcccc}
\hline & \multicolumn{3}{c}{ RI category } & \\
\cline { 2 - 3 } Item & Low RI & Medium RI & High RI & $P$-value \\
\hline RI1 & $0.43(0.38-0.50)$ & $0.69(0.62-0.76)$ & - & $<0.0001$ \\
Pregnant at AI1 & $0.61(0.52-0.72)$ & $0.89(0.79-1.01)$ & - & $<0.0001$ \\
Pregnant at AI2 & $1.51(1.06-2.15)$ & $1.29(0.99-1.69)$ & - & 0.058 \\
Pregnancy loss following AI1 & $2.16(1.37-3.41)$ & $1.58(1.08-2.31)$ & - & 0.004 \\
Pregnancy loss following AI2 & $0.23(0.26-0.34)$ & $0.69(0.62-0.94)$ & - & $<0.0001$ \\
RI2 & $0.63(0.53-0.74)$ & $0.92(0.79-1.07)$ & - & $<0.0001$ \\
Pregnant following AI1 & $2.26(1.52-3.36)$ & $1.78(1.29-2.46)$ & - & $<0.0001$ \\
Pregnant following AI2 & $1.76(1.08-2.86)$ & $1.62(1.03-2.55)$ & - & 0.051 \\
Pregnancy loss following AI1 & - &
\end{tabular}

${ }^{1}$ Low RI $=$ cows in the lowest quartile (RI $<0.26$ and RI $\left.<0.28\right) ;$ medium RI $=$ cows within the interquartile range $(0.26 \geq \mathrm{RI} 1 \leq 0.39$ and $0.28 \geq \mathrm{RI} 2 \leq 0.40)$; high $\mathrm{RI}=$ cows in the top quartile (RI1 $>0.39$ and RI2 $>$ 0.40). The final model included parity and season of calving as fixed effects and herd and region as random effects. 
the effect of clinical endometritis on reproduction has gained increased attention in recent years because of prolonged time to pregnancy, reduced likelihood of conception, and increased risk for pregnancy loss (Bonnett et al., 1993; Galvão et al., 2009; Bicalho et al., 2016). Interestingly, both indices included these 3 disorders, which are sequential in time and interrelated, supporting the idea of an additive detrimental effect when these conditions coincide in an individual.

Another trait that was included in both RI was time to resumption of ovulation after calving. Risk factors for postpartum anovulation include severity of negative energy balance after calving and a longer interval to its nadir (Beam and Butler, 1997), as well as uterine infection and inflammation (Sheldon et al., 2002). These variables have been consistently associated with reduced fertility in dairy cows (Thatcher and Wilcox, 1973; Galvão et al., 2010), which may be part of the reason several studies have shown that anovulation resulted in decreased pregnancy per AI, increased pregnancy loss, and increased time to pregnancy (Darwash et al., 1997; Galvão et al., 2004, 2010; Santos et al., 2004; Gilbert et al., 2005).

Overall, the negative influence of diseases and delayed resumption of ovulation after calving was properly represented in the resulting RI values. Our analyses showed consistent agreement between categories of the developed indices and the performance variables under analysis.

In general, the analyses indicated that high RI categories had shorter intervals from calving to first service and from calving to conception, and smaller numbers of services per conception (Figures 1 and 2). Notably, the categorization in RI2 did not result in different CFSI values for MRI2 compared with HRI2, but the differences for CCI were significant for all categories in both indices. Overall, the differences in CFSI were smaller than the variation in CCI. A possible explanation may be the use of a standardized ovulation synchronization program, which partially overrides the effect of anovulation on insemination rate but not on pregnancy per AI, as all cows are submitted to AI regardless of any potential difference in individual cow fertility (Santos et al., 2009).

In both indices, cows with high RI categories had greater proportions of pregnancy at first and second AI. However, the differences in pregnancy among categories of both RI are greater for AI1 compared with the differences determined for pregnancy at AI2. This trend could be explained by a closer temporal proximity between the peripartum variables in the indices and AI1 compared with AI2, in which other factors may play a role in conception.
Interestingly, cows in LRI or MRI categories had greater odds of losing their pregnancy after first and second AI than HRI cows. Pregnancy loss was not included in either RI, but it is plausible to consider the potential for associations between health events occurring early in lactation and subsequent embryo mortality or failure to maintain pregnancy. Multiple reports indicated that not only disorders of the reproductive tract but also disorders occurring in other systems, such as subclinical ketosis, resulted in increased pregnancy losses (Risco et al., 1999; Santos and Ribeiro, 2014). Moreover, Ribeiro et al. (2016) highlighted the carryover consequences of diseases occurring before breeding on developmental biology, with potential effects lasting up to 4 mo.

Some research has indicated an antagonistic relationship between milk yield and fertility (Lucy, 2001; Butler, 2003), but other authors have reported a positive relationship for these 2 variables (Campbell et al., 2009; Cook and Green, 2016). Overall, the direction of this association remains controversial, at least in part due to the confounding role of disease occurrence (Dubuc et al., 2011). In the present experiment, milk yield was not included as a predictive variable in RI1. For RI1, average milk yield until 90 DIM was lower for cows in LRI1, but no difference was detected between MRI1 and HRI1. The lower level of production in LRI1 cows could be an indication of worse transitioning during the beginning of lactation but could be also an indication of lower potential for milk yield. Interestingly, the magnitude of the increase in milk yield from TDM2 to TDM3, which was greater in LRI $(2.28 \mathrm{~kg})$ than in MRI $(1.08 \mathrm{~kg})$ and HRI $(0.83 \mathrm{~kg})$, may indicate that these cows were recovering from poor transition as lactation advanced. The model for RI2 included milk yield at the first milk test after calving as a predictor. In contrast to the RI1 outcome, differences in M90 were only detected for MRI2 compared with HRI2. As for LRI, the greatest change in milk yield between TDM2 and TDM3 was observed in LRI2, which may be indicative of recovery following an inadequate transition $(2.58 \mathrm{~kg}$ vs. $0.93 \mathrm{~kg}$ and $1.34 \mathrm{~kg}$ for MRI and HRI, respectively).

A negative association between the occurrence of early-lactation disease events and subsequent survival has been widely reported (Pinedo et al., 2010; Carvalho et al., 2019). Moreover, low reproductive performance has consistently been identified as a significant risk for culling. In a study by De Vries et al. (2010), the analysis of a large DHI data set indicated that pregnant cows had 3 to 7 times lower hazards of culling than open cows. Hazards of culling increased for cows that had calving difficulty, gave birth to males or twins, or had a greater number of days to conception. Our results, 
involving more than 10,000 cows across 4 regions of the United States, utilizing a prospective experimental design, agree with these reported associations. In the present study, both indices showed a clear tendency toward improved survival from LRI to HRI, with differences of $15.6 \mathrm{~d}$ and $7 \mathrm{~d}$ between these 2 categories in RI1 and RI2, respectively. Similarly, when cow survival is analyzed across DIM, the distance among categories consistently increases as the lactation progresses.

\section{CONCLUSIONS}

Consistent agreements were evident between categories of the developed RI and measurements of fertility of Holstein cows. Therefore, the proposed approach of utilizing integrated responses as an RI is a viable methodology to refine the allocation of cows into low- and high-fertility populations, allowing selection of cows for genotyping investigation of fertility-related traits. This is a useful tool to assist in phenotypic determination of fertility-related traits in making herd management decisions to optimize herd performance and profitability.

\section{ACKNOWLEDGMENTS}

The authors acknowledge the USDA National Institute of Food and Agriculture (NIFA) Agriculture and Food Research Initiative (AFRI) Translational Genomics for Improved Fertility of Animals (grant \#201368004; Washington, DC) for financial support to perform the phenotyping of the study animals. We thank the participant dairy herds that allowed continuous weekly monitoring of cows. The authors declare that they have no competing interests.

\section{REFERENCES}

Beam, S. W., and W. R. Butler. 1997. Energy balance and ovarian follicle development prior to the first ovulation postpartum in dairy cows receiving three levels of dietary fat. Biol. Reprod. 56:133-142. https://doi.org/10.1095/biolreprod56.1.133.

Bell, A. W., R. Slepetis, and R. A. Ehrhardt. 1995. Growth and accretion of energy and protein in the gravid uterus during late pregnancy in Holstein cows. J. Dairy Sci. 78:1954-1961. https://doi .org/10.3168/jds.S0022-0302(95)76821-7.

Bicalho, M. L. S., F. S. Lima, V. S. Machado, E. B. Meira Jr., E. K. Ganda, C. Foditsch, R. C. Bicalho, and R. O. Gilbert. 2016. Associations among Trueperella pyogenes, endometritis diagnosis, and pregnancy outcomes in dairy cows. Theriogenology 85:267-274. https://doi.org/10.1016/j.theriogenology.2015.09.043.

Bicalho, R. C., S. H. Cheong, G. Cramer, and C. L. Guard. 2007. Association between a visual and an automated locomotion score in lactating Holstein cows. J. Dairy Sci. 90:3294-3300. https://doi .org/10.3168/jds.2007-0076.

Bicalho, R. C., S. H. Cheong, K. N. Galvão, L. D. Warnick, and C. L. Guard. 2007a. Effect of twin birth calvings on milk production, reproductive performance, and survival of lactating cows. J. Am. Vet. Med. Assoc. 231:1390-1397. https://doi.org/10.2460/javma .231.9.1390.
Bicalho, R. C., K. N. Galvao, C. L. Guard, and J. E. Santos. 2008. Optimizing the accuracy of detecting a functional corpus luteum in dairy cows. Theriogenology 70:199-207. https://doi.org/10.1016/j .theriogenology.2008.03.015.

Bonnett, B. N., S. Wayne Martin, and A. H. Meek. 1993. Associations of clinical findings, bacteriological and histological results of endometrial biopsy with reproductive performance of postpartum dairy cows. Prev. Vet. Med. 15:205-220. https://doi.org/10.1016/ 0167-5877(93)90114-9.

Brotzman, R. L., N. B. Cook, K. Nordlund, T. B. Bennett, A. Gomez Rivas, and D. Döpfer. 2015. Cluster analysis of Dairy Herd Improvement data to discover trends in performance characteristics in large Upper Midwest dairy herds. J. Dairy Sci. 98:3059-3070. https://doi.org/10.3168/jds.2014-8369.

Butler, W. R. 2003. Energy balance relationships with follicular development, ovulation and fertility in postpartum dairy cows. Livest. Prod. Sci. 83:211-218. https://doi.org/10.1016/S0301 -6226(03)00112-X.

Campbell, M. S., K. Hand, D. F. Kelton, F. Miglior, and S. J. LeBlanc. 2009. The association of level of milk production with reproductive performance. J. Dairy Sci. 92(E-Suppl. 1):335. (Abstr.)

Carvalho, M. R., F. Peñagaricano, J. E. P. Santos, T. J. DeVries, B. W. McBride, and E. S. Ribeiro. 2019. Long-term effects of postpartum clinical disease on milk production, reproduction, and culling of dairy cows. J. Dairy Sci. 102:11701-11717. https://doi .org/10.3168/jds.2019-17025.

Cerri, R. L., J. E. P. Santos, S. O. Juchem, K. N. Galvao, and R. C. Chebel. 2004. Timed artificial insemination with estradiol cypionate or insemination at estrus in high-producing dairy cows. J. Dairy Sci. 87:3704-3715. https://doi.org/10.3168/jds.S0022 -0302(04)73509-2.

Cook, J. G., and M. J. Green. 2016. Use of early lactation milk recording data to predict the calving to conception interval in dairy herds. J. Dairy Sci. 99:4699-4706. https://doi.org/10.3168/jds .2015-10264.

Darwash, A. O., G. E. Lamming, and J. A. Woolliams. 1997. The phenotypic association between the interval to postpartum ovulation and traditional measures of fertility in dairy cattle. Anim. Sci. 65:9-16. https://doi.org/10.1017/S1357729800016234.

De Vries, A., J. D. Olson, and P. J. Pinedo. 2010. Reproductive risk factors for culling and productive life in large dairy herds in the eastern United States between 2001 and 2006. J. Dairy Sci. 93:613-623. https://doi.org/10.3168/jds.2009-2573.

Dechow, C. D., and R. C. Goodling. 2008. Mortality, culling by sixty days in milk, and production profiles in high- and low-survival Pennsylvania herds. J. Dairy Sci. 91:4630-4639. https://doi.org/ 10.3168/jds.2008-1337.

Diskin, M. G., J. J. Murphy, and J. M. Sreenan. 2006. Embryo survival in dairy cows managed under pastoral conditions. Anim. Reprod. Sci. 96:297-311. https://doi.org/10.1016/j.anireprosci.2006 .08.008.

Dubuc, J., T. F. Duffield, K. E. Leslie, J. S. Walton, and S. J. LeBlanc. 2010. Risk factors for postpartum uterine diseases in dairy cows. J. Dairy Sci. 93:5764-5771. https://doi.org/10.3168/jds.2010-3429.

Dubuc, J., T. F. Duffield, K. E. Leslie, J. S. Walton, and S. J. LeBlanc. 2011. Effects of postpartum uterine diseases on milk production and culling in dairy cows. J. Dairy Sci. 94:1339-1346. https://doi .org $/ 10.3168 / \mathrm{jds} .2010-3758$.

Esposito, G., P. C. Irons, E. C. Webb, and A. Chapwanya. 2014. Interactions between negative energy balance, metabolic diseases, uterine health and immune response in transition dairy cows. Anim. Reprod. Sci. 144:60-71. https://doi.org/10.1016/j.anireprosci.2013 .11.007.

Ferguson, J. D., D. T. Galligan, and N. Thomsen. 1994. Principal descriptors of body condition score in Holstein cows. J. Dairy Sci. 77:2695-2703. https://doi.org/10.3168/jds.S0022-0302(94)77212 $-\mathrm{X}$.

Fourichon, C., H. Seegers, and X. Malher. 2000. Effect of disease on reproduction in the dairy cow: A meta-analysis. Theriogenology 53:1729-1759. https://doi.org/10.1016/S0093-691X(00)00311-3. 
Galvão, K. N., M. Frajblat, W. R. Butler, S. B. Brittin, C. L. Guard, and R. O. Gilbert. 2010. Effect of early postpartum ovulation on fertility in dairy cows. Reprod. Domest. Anim. 45:e207-e211.

Galvão, K. N., L. F. Greco, J. M. Vilela, M. F. Sá Filho, and J. E. P. Santos. 2009. Effect of intrauterine infusion of ceftiofur on uterine health and fertility in dairy cows. J. Dairy Sci. 92:1532-1542. https://doi.org/10.3168/jds.2008-1615.

Galvão, K. N., J. E. P. Santos, S. O. Juchem, R. L. Cerri, A. C. Coscioni, and M. Villasenor. 2004. Effect of addition of a progesterone intravaginal insert to a timed insemination protocol using estradiol cypionate on ovulation rate, pregnancy rate, and late embryonic loss in lactating dairy cows. J. Anim. Sci. 82:3508-3517. https://doi.org/10.2527/2004.82123508x.

Gilbert, R. O. 2019. Symposium review: Mechanisms of disruption of fertility by infectious diseases of the reproductive tract. J. Dairy Sci. 102:3754-3765. https://doi.org/10.3168/jds.2018-15602.

Gilbert, R. O., S. T. Shin, C. L. Guard, H. N. Erb, and M. Frajblat. 2005. Prevalence of endometritis and its effects on reproductive performance of dairy cows. Theriogenology 64:1879-1888. https:// doi.org/10.1016/j.theriogenology.2005.04.022.

Gröhn, Y. T., S. W. Eicker, V. Ducrocq, and J. A. Hertl. 1998. Effect of diseases on the culling of Holstein dairy cows in New York State. J. Dairy Sci. 81:966-978. https://doi.org/10.3168/jds.S0022 -0302(98) 75657-7.

Gröhn, Y. T., and P. J. Rajala-Schultz. 2000. Epidemiology of reproductive performance in dairy cows. Anim. Reprod. Sci. 61:605614. https://doi.org/10.1016/S0378-4320(00)00085-3.

Gröhn, Y. T., P. J. Rajala-Schultz, H. G. Allore, M. A. DeLorenzo, J. A. Hertl, and D. T. Galligan. 2003. Optimizing replacement of dairy cows: Modeling the effects of diseases. Prev. Vet. Med. 61:27-43. https://doi.org/10.1016/S0167-5877(03)00158-2.

Kelton, D. F., K. D. Lissemore, and R. E. Martin. 1998. Recommendations for recording and calculating the incidence of selected clinical diseases of dairy cattle. J. Dairy Sci. 81:2502-2509. https://doi .org/10.3168/jds.S0022-0302(98)70142-0.

Lucy, M. C. 2001. Reproductive loss in high-producing dairy cattle: Where will it end? J. Dairy Sci. 84:1277-1293. https://doi.org/10 .3168/jds.S0022-0302(01)70158-0.

Lukas, J. M., J. K. Reneau, R. L. Wallace, and A. De Vries. 2015. A study of methods for evaluating the success of the transition period in early-lactation dairy cows. J. Dairy Sci. 98:250-262. https: //doi.org/10.3168/jds.2014-8522.

McDougall, S., R. Macaulay, and C. Compton. 2007. Association between endometritis diagnosis using a novel intravaginal device and reproductive performance in dairy cattle. Anim. Reprod. Sci. 99:9 23. https://doi.org/10.1016/j.anireprosci.2006.03.017.

Moyes, K. M., T. Larsen, and K. L. Ingvartsen. 2013. Generation of an index for physiological imbalance and its use as a predictor of primary disease in dairy cows during early lactation. J. Dairy Sci. 96:2161-2170. https://doi.org/10.3168/jds.2012-5646.

Nordlund, K. V. 2006. Transition Cow Index. Pages 139-143 in 39th Proc. Am. Assoc. Bovine Practitioners, St. Paul, MN. Frontier Printers, Stillwater, OK.

Nordlund, K. V., T. B. Bennett, G. R. Oetzel, M. K. Clayton, and N. B. Cook. 2011. Method for optimizing health and productivity of milk producing animals. Wisconsin Alumni Research Foundation, assignee. United States patent no. 7886691.

Nordlund, K. V., and N. B. Cook. 2004. Using herd records to monitor transition cow survival, productivity, and health. Vet. Clin. North Am. Food Anim. Pract. 20:627-649. https://doi.org/10.1016/j .cvfa.2004.06.012.

Norman, H. D., J. R. Wright, S. M. Hubbard, R. H. Miller, and J. L. Hutchison. 2009. Reproductive status of Holstein and Jersey cows in the United States. J. Dairy Sci. 92:3517-3528. https://doi.org/ 10.3168/jds.2008-1768.

Overton, T. R., J. A. A. McArt, and D. V. Nydam. 2017. A 100year review: Metabolic health indicators and management of dairy cattle. J. Dairy Sci. 100:10398-10417. https://doi.org/10.3168/jds .2017-13054.
Pinedo, P. J., and A. de Vries. 2010. Effect of days to conception in the previous lactation on the risk of death and live culling around calving. J. Dairy Sci. 93:968-977. https://doi.org/10.3168/jds .2009-2408.

Pinedo, P. J., A. de Vries, and D. W. Webb. 2010. Dynamics of culling risk with disposal codes reported by Dairy Herd Improvement dairy herds. J. Dairy Sci. 93:2250-2261. https://doi.org/10.3168/ jds.2009-2572.

Ribeiro, E. S., G. Gomes, L. F. Greco, R. L. A. Cerri, A. Vieira-Neto, P. L. J. Monteiro Jr., F. S. Lima, R. S. Bisinotto, W. W. Thatcher, and J. E. P. Santos. 2016. Carryover effect of postpartum inflammatory diseases on developmental biology and fertility in lactating dairy cows. J. Dairy Sci. 99:2201-2220. https://doi.org/10.3168/ jds.2015-10337.

Ribeiro, E. S., F. S. Lima, L. F. Greco, R. S. Bisinotto, A. P. A. Monteiro, M. Favoreto, H. Ayres, R. S. Marsola, N. Martinez, W. W. Thatcher, and J. E. P. Santos. 2013. Prevalence of periparturient diseases and effects on fertility of seasonally calving grazing dairy cows supplemented with concentrates. J. Dairy Sci. 96:5682-5697. https://doi.org/10.3168/jds.2012-6335.

Risco, C. A., G. A. Donovan, and J. Hernandez. 1999. Clinical mastitis associated with abortion in dairy cows. J. Dairy Sci. 82:1684-1689. https://doi.org/10.3168/jds.S0022-0302(99)75397-X

Roberts, T., N. Chapinal, S. J. LeBlanc, D. F. Kelton, J. Dubuc, and T. F. Duffield. 2012. Metabolic parameters in transition cows as indicators for early-lactation culling risk. J. Dairy Sci. 95:30573063. https://doi.org/10.3168/jds.2011-4937.

Royal, M. D., A. P. Flint, and J. A. Woolliams. 2002. Genetic and phenotypic relationships among endocrine and traditional fertility traits and production traits in Holstein-Friesian dairy cows. J. Dairy Sci. 85:958-967. https://doi.org/10.3168/jds.S0022 -0302(02)74155-6.

Santos, J. E. P., R. S. Bisinotto, E. S. Ribeiro, F. S. Lima, L. F. Greco, C. R. Staples, and W. W. Thatcher. 2010. Applying nutrition and physiology to improve reproduction in dairy cattle. Soc. Reprod. Fertil. Suppl. 67:387-403. https://doi.org/10.5661/RDR-VII-387.

Santos, J. E. P., and E. S. Ribeiro. 2014. Impact of animal health on reproduction in dairy cows. Anim. Reprod. 11:254-269.

Santos, J. E. P., H. M. Rutigliano, and M. F. Sá Filho. 2009. Risk factors for resumption of postpartum estrous cycles and embryonic survival in lactating dairy cows. Anim. Reprod. Sci. 110:207-221. https://doi.org/10.1016/j.anireprosci.2008.01.014.

Santos, J. E. P., W. W. Thatcher, R. C. Chebel, R. L. Cerri, and K. N. Galvão. 2004. The effect of embryonic death rates in cattle on the efficacy of estrus synchronization programs. Anim. Reprod. Sci 83:513-535. https://doi.org/10.1016/j.anireprosci.2004.04.015.

Schultz, K. K., T. B. Bennett, K. V. Nordlund, D. Döpfer, and N. B. Cook. 2016. Exploring relationships between Dairy Herd Improvement monitors of performance and the Transition Cow Index in Wisconsin dairy herds. J. Dairy Sci. 99:7506-7516. https://doi .org/10.3168/jds.2015-10680.

Sheldon, I. M., D. E. Noakes, A. N. Rycroft, D. U. Pfeiffer, and H. Dobson. 2002. Influence of uterine bacterial contamination after parturition on ovarian dominant follicle selection and follicle growth and function in cattle. Reproduction 123:837-845. https:/ /doi.org/10.1530/rep.0.1230837.

Thatcher, W. W., and C. J. Wilcox. 1973. Postpartum estrus as indicator of reproductive status in the dairy cow. J. Dairy Sci. 56:608610. https://doi.org/10.3168/jds.S0022-0302(73)85227-0.

Weigel, K. A. 2006. Prospects for improving reproductive performance through genetic selection. Anim. Reprod. Sci. 96:323-330. https:/ /doi.org/10.1016/j.anireprosci.2006.08.010.

Wisnieski, L., B. Norby, S. J. Pierce, T. Becker, J. C. Gandy, and L. M. Sordillo. 2019. Predictive models for early lactation diseases in transition dairy cattle at dry-off. Prev. Vet. Med. 163:68-78. https: //doi.org/10.1016/j.prevetmed.2018.12.014. 